\title{
RELAÇÕES ENTRE A FLORÍSTICA ARBÓREA E CARACTERÍSTICAS DO SOLO EM UM FRAGMENTO DE FLORESTA ATLÂNTICA, TAMANDARÉ - PE
}

\author{
Lucineide de Jesus Teixeira ${ }^{1}$, Ana Lícia Patriota Feliciano ${ }^{2}$, Izabel Cristina de Luna Galindo ${ }^{3}$, \\ Carolina Malala Martins ${ }^{4}$, Antonia Lidiane de Alencar ${ }^{5}$ \\ ${ }^{1}$ Eng ${ }^{a}$ Agrônoma, M.Sc., Jardim Botânico de Salvador, Salvador, BA, Brasil - lucineide-teixeira@ibest.com.br \\ ${ }^{2}$ Eng $^{\mathrm{a}}$ Florestal, Dr ${ }^{\mathrm{a}}$., Depto. de Ciências Florestais, UFRPE, Recife, PE, Brasil - licia@ dcfl.ufrpe.br \\ ${ }^{3}$ Eng $^{a}$ Agrônoma, Dr., Depto. de Solos, UFRPE, Recife, PE, Brasil - izabelgalindo@ solos.ufrpe.br \\ ${ }^{4}$ Enga $^{\mathrm{a}}$ Agrônoma, M.Sc., UFRPE, Recife, PE, Brasil - carolmalala@ hotmail.com \\ ${ }^{5}$ Bióloga, M.Sc., UFRPE, Recife, PE, Brasil - lidyalencar@yahoo.com.br \\ Recebido para publicação: 29/05/2009 - Aceito para publicação: 24/11/2009
}

\begin{abstract}
Resumo
O presente trabalho objetivou relacionar, ao longo de um gradiente topográfico, a florística do componente arbóreo com as características físicas e químicas do solo em um fragmento de Floresta Ombrófila Densa, na Reserva Biológica de Saltinho, Pernambuco. O levantamento florístico foi realizado em 42 parcelas, distribuídas em um gradiente de três posições topográficas considerando os indivíduos arbóreos vivos, com CAP $\geq 15 \mathrm{~cm}$. A vegetação foi analisada pela similaridade florística utilizando a distância euclidiana e o solo pelas médias das variáveis físicas e químicas. A relação entre as variáveis químicas do solo e a vegetação deu-se por análise de correspondência canônica. A encosta e o topo foram as posições com maior similaridade florística. Ocorreram espécies com desenvolvimento preferencial na baixada, pela fertilidade do solo e no topo, pelo teor de carbono orgânico e em ambas pelo teor de umidade atual.

Palavras-chave: Floresta Atlântica; análise físico-química do solo; similaridade florística; relação solo vegetação.
\end{abstract}

\begin{abstract}
Relationships between tree floristic and soil characteristics in an Atlantic Forest patch, Tamandaré, Pernambuco, Brazil. This study aimed to relate the tree components flora with the physical and chemical characteristics of soil over a topographic gradient, in a patch of dense rain forest in the Saltinho Biological Reserve, Pernambuco State. The floristic survey was carried out in 42 plots distributed in a gradient of three topographic positions, for those individual living trees with DBH $\geq$ $15 \mathrm{~cm}$. The vegetation floristic similarity was analyzed by using the Euclidean distance and the soil by means of physical and chemical variables. The relationship between the chemical variables of soil and vegetation was done by canonical correlation. The slope and the top were the positions with higher floristic similarity. Species occurred with preferential development in the flatland, because of the soil fertility and on the top, due to the organic carbon grade and in the both positions, because of the moisture.
\end{abstract}

Keywords: Atlantic forest; physical-chemical analysis; floristic similarity; soil vegetation ratio.

\section{INTRODUÇÃO}

Variações na vegetação estão diretamente relacionadas com os solos e as condições do relevo, refletindo características, como, por exemplo, a profundidade efetiva do solo e a presença ou ausência de lençol d'água superficial ou subsuperficial (ROSSI; QUEIROZ NETO, 2001). Ao caracterizar a composição florística de um fragmento de mata atlântica, na APA Barra do Rio Mamanguape (PB), Pereira; Alves (2007) perceberam que houve um predomínio de vegetação com porte arbóreo-arbustivo, e que essa característica sofria alterações em função do ambiente. Nas áreas mais íngremes e declivosas, 
próximas de cursos d'água, encontraram-se árvores de maior porte, enquanto que nas áreas planas predominaram árvores com porte mais baixo.

Analisando a composição florística e os fatores que estariam determinando a ocorrência da vegetação em um gradiente florestal, Moreno; Schiavini (2001) observaram que o solo é um forte fator determinante na distribuição da vegetação, e esta, por sua vez, estaria provavelmente associada à disponibilidade de água e à interferência da luz em regiões de borda.

Resende et al. (2002) tentaram compreender os ecossistemas que compõem a Floresta Atlântica, com base em informações pedológicas, estratificando diferentes ambientes, utilizando o solo como fonte de recursos hídricos e nutricionais. Inferiram que as classes de solos poderiam variar em pequenas distâncias, tornando-se bem rasos, ou com afloramentos rochosos, ou profundos, bem como distróficos ou eutróficos. Com relação às características topográficas, afirmaram que elas poderiam originar padrões intrincados de disponibilidade de recursos, como radiação solar direta, água e nutrientes, que influenciam, por exemplo, na vegetação e na biodiversidade. Sobre a vegetação, juntamente com o relevo, perceberam a formação de grupos indicadores de ambientes, e que os solos enfatizaram a relação vegetação-relevo com as características de disponibilidade de água e nutrientes.

Em um estudo de correlação entre a composição florística e as variáveis químicas do solo (pH, $\mathrm{P}$, $\mathrm{K}, \mathrm{Ca}, \mathrm{Mg}, \mathrm{Al}$ e acidez potencial), Campos et al. (2006) observaram que, na presença de maiores teores de $\mathrm{Ca}$ e $\mathrm{Mg}$, algumas espécies se apresentaram mais abundantes, ou seja, consideraram que essas espécies eram mais exigentes em ambientes de maior fertilidade nos solos. $\mathrm{O}$ teor de nutrientes influencia diretamente a composição florística e a distribuição das espécies nos solos (DUARTE, 2007).

No presente trabalho, objetivou-se relacionar, ao longo de um gradiente topográfico, a florística do componente arbóreo com as características físicas e químicas do solo em um fragmento de Floresta Ombrófila Densa, em Tamandaré, Pernambuco.

\section{MATERIAL E MÉTODOS}

O estudo foi desenvolvido na Reserva Biológica de Saltinho, localizada nos municípios de Tamandaré e Rio Formoso, PE, com área total de 475 ha (Figura 1). A área experimental foi de aproximadamente 30 ha, localizada na zona intangível Mata Alta, trecho inserido no município de Tamandaré. O predomínio é de clima tropical úmido (As'), com pluviosidade média de $1500 \mathrm{~mm}$, temperatura média anual de $25^{\circ} \mathrm{C}$, umidade relativa de 65 a $60 \%$ (CPRH, 2001; IBAMA, 2003). O relevo é levemente ondulado, com altitudes variando de 40 a $120 \mathrm{~m}$ (IBAMA, 2003). A tipologia florestal é ombrófila densa de terras baixas (VELOSO et al., 1991). Os solos predominantes são os Latossolos Vermelho-Amarelos distróficos. No gradiente topográfico, foram implantadas 42 parcelas de $250 \mathrm{~m}^{2}$, sendo 14 por posição, que foram denominadas de baixada, encosta e topo, definidas a partir de cartas planialtimétricas da área de estudo (FEITOSA, 2004; MARANGON et al., 2007).

O levantamento da vegetação arbórea considerou os indivíduos vivos, com circunferência à altura do peito (CAP) igual ou superior a $15 \mathrm{~cm}$, utilizando-se uma trena de bolso para a medição. $\mathrm{O}$ material botânico dos indivíduos mensurados foi identificado por meio de bibliografias especializadas e morfologia comparada, com auxílio de lupa e análises de exsicatas, nos Herbários Sérgio Tavares (HSTUFRPE) e Dárdano de Andrade Lima (IPA), e também identificadas por especialistas. A classificação seguiu as regras do sistema Cronquist (1988), e os nomes das espécies foram conferidos em Barbosa et al. (2006) e Mobot (2008).

Realizou-se a análise de similaridade florística da vegetação arbórea por meio de dendrogramas, no gradiente topográfico, cujos dados partiram da formação de uma matriz de presença e ausência das espécies, utilizando-se a distância euclidiana como medida de dissimilaridade e o algoritmo de agrupamento de Ward, com auxílio do programa PC-Ord for Windows versão 4.14 (MCCUNE; MEFFORD, 1999).

No solo, realizou-se uma amostragem por posição topográfica nas profundidades de $0-10 \mathrm{~cm}$, 10-30 cm e 30-60 cm, totalizando 126 amostras para as análises físicas e químicas (Figura 2). As características físicas analisadas foram: umidade atual (U), areia, silte e argila. As características químicas foram: $\mathrm{pH}$ em água por potenciometria, cálcio $(\mathrm{Ca})$ e magnésio $(\mathrm{Mg})$ por espectrofotometria de absorção atômica, alumínio $(\mathrm{Al})$ por titulometria com hidróxido de sódio, potássio $(\mathrm{K})$ por fotometria de chama, fósforo (P) por colorimetria segundo Braga; Defelipo (1974), carbono orgânico total (COT) pela oxidação 
do carbono orgânico por dicromato de potássio na presença de ácido sulfúrico concentrado segundo Yeomans; Bremner (1988) e acidez potencial $(\mathrm{H}+\mathrm{Al})$ por extração com solução de acetato de cálcio (EMBRAPA, 1997). As análises físicas e químicas foram realizadas, respectivamente, nos laboratórios de Física e Química dos Solos, do Departamento de Agronomia da Universidade Federal Rural de Pernambuco (UFRPE).

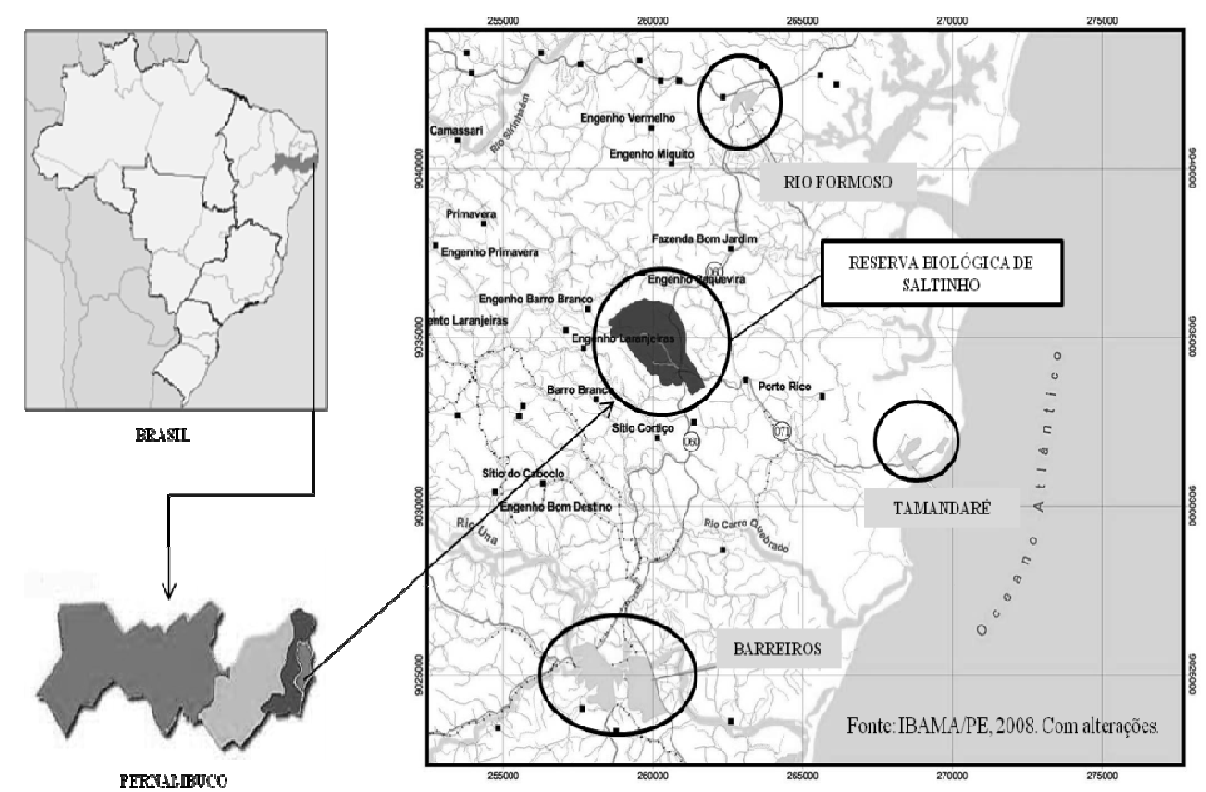

Figura 1. Localização da Reserva Biológica de Saltinho, nos municípios de Tamandaré e Rio Formoso, Pernambuco, Brasil.

Figure 1. Location of the Saltinho Biological Reserve, in the municipalities Tamandare and Rio Formoso, Pernambuco, Brazil.

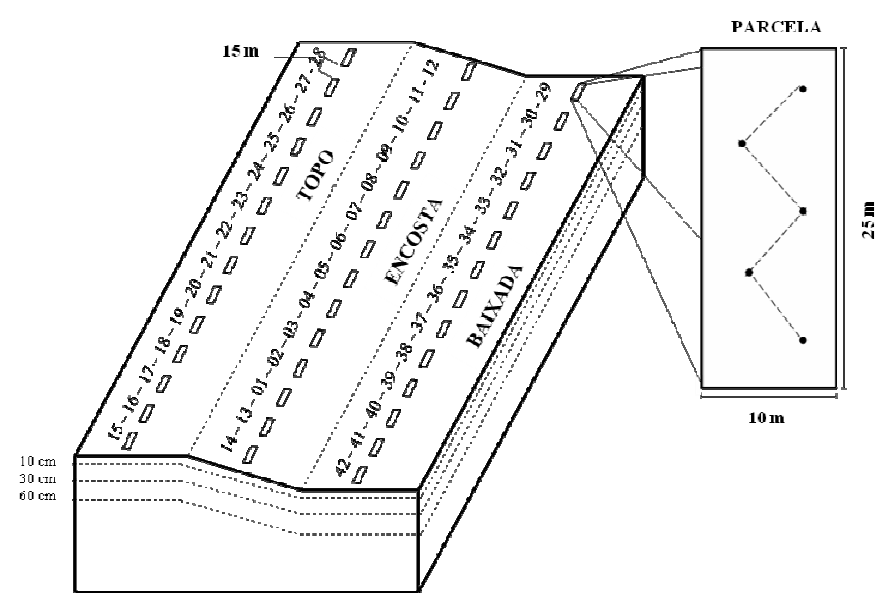

Figura 2. Esquema da amostragem dos solos no gradiente topográfico estudado na Mata Alta, Tamandaré, Pernambuco.

Figure 2. Scheme of the sampling of soils in the studied topographic gradient in Mata Alta, Tamandare, Pernambuco, Brazil.

As propriedades físicas e químicas do solo foram submetidas a uma análise de variância (ANOVA) com teste de comparação de médias de Tukey $(\mathrm{p}<0,01)$, considerando as diferentes profundidades e as três posições topográficas (DUARTE, 2007). 
A relação entre a vegetação arbórea e o solo, nas posições topográficas, foi analisada utilizandose uma análise de correspondência canônica - CCA (VALENTIN, 2000). Neste estudo, foi utilizado o programa PC-Ord for Windows versão 4.14 (MCCUNE; MEFFORD, 1999), produzindo-se uma matriz de vegetação e uma de variáveis do solo com base em Cunha et al. (2003). Na matriz de vegetação, utilizou-se a densidade absoluta das espécies que apresentaram no mínimo 12 indivíduos, pois, segundo Gauch (1982), espécies com número reduzido de indivíduos apresentam pouca ou nenhuma influência sobre resultados de agrupamentos. Na matriz das variáveis do solo, utilizaram-se apenas as médias das propriedades químicas calculadas entre as faixas de profundidades por parcela.

\section{RESULTADOS E DISCUSSÃO}

A similaridade florística foi encontrada em maior ou menor percentual em todas as parcelas na faixa de distância acima de 3\% (Figura 3). Pinto-Coelho (2000) supôs que, se as unidades amostrais que compõem uma comunidade são similares, então muitas ou todas as espécies têm distribuições similares. A similaridade florística entre as posições topográficas sugere que a maior semelhança ocorreu entre a encosta e o topo.

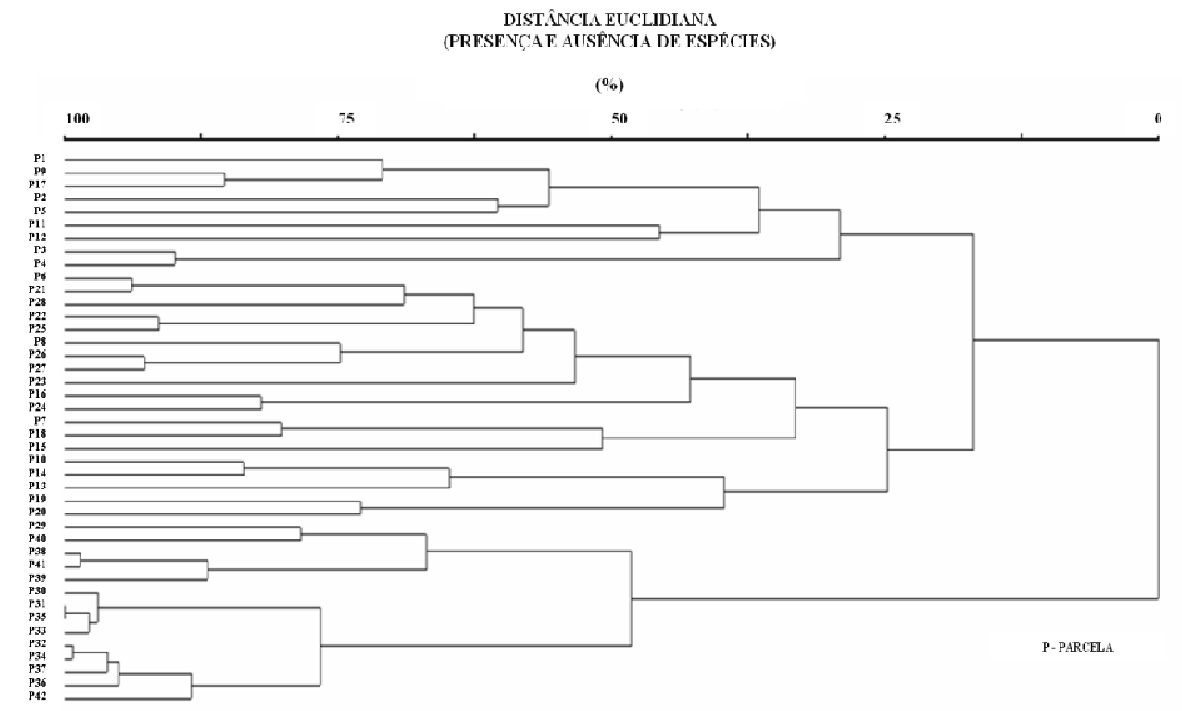

Figura 3. Dendrograma de dissimilaridade pelo Método Ward, baseado na presença e ausência de espécies utilizando a distância euclidiana entre as 42 parcelas amostradas no trecho da Mata Alta, Tamandaré, Pernambuco, Brasil.

Figure 3. Dendrogram of dissimilarity by Ward method, based on the presence and absence of species using the Euclidean distance between the 42 sampled plots in the Mata Alta, Tamandare, Pernambuco, Brazil.

Os resultados de similaridade florística demonstraram que o primeiro grupo de parcelas contempla a encosta (P1 até P14) e o topo (P15 até P28), e o segundo grupo a baixada (P29 até P42). A encosta e o topo apresentaram condições ambientais mais conservadas, quando comparadas à baixada. Nesta última, existem características de intervenções antrópicas, maior acessibilidade e presença de espécies exóticas, principalmente frutíferas.

Nos subgrupos, verifica-se que o maior deles é composto pelas parcelas do topo, exceto a 17, e por seis parcelas da encosta. As parcelas com maior similaridade florística $(\mathrm{d}<3 \%)$ ocorreram na baixada, e as com menor ( $>$ > 37\%), na encosta, ressaltando-se que essas áreas apresentaram, respectivamente, menor e maior riqueza de espécies no gradiente topográfico. Entre as parcelas de similaridade intermediária $(6<\mathrm{d}<28 \%)$, relacionaram-se dez pares de parcelas, dos quais apenas três foram entre diferentes posições no relevo (6 com 21, 7 com 18 e 9 com 17), sugerindo-se que as semelhanças podem estar relacionadas com a disposição das parcelas no relevo (SIQUEIRA, 2001). 
$\mathrm{Na}$ análise física dos solos, os resultados indicaram que a umidade atual não mostrou diferenças significativas nas profundidades estudadas, entretanto observaram-se, para as diferentes posições topográficas, valores médios superiores e significativos para a baixada (34\%) e o topo (36\%). A encosta apresentou o valor médio inferior de $28 \%$. Os teores de areia, silte e argila também não mostraram diferenças significativas nas profundidades estudadas, entretanto os valores médios de areia $(49,14 \%)$ e silte $(10,55 \%)$ foram significativamente superiores na posição de baixada. Contrariamente, o teor médio de argila $(66,43 \%)$ foi significativamente superior na posição topo. A posição de encosta apresentou valores intermediários de areia, silte e argila: $41,27 \%, 7,73 \%$ e 51,00\%, respectivamente.

Os resultados obtidos para a posição de baixada concordam com Curcio et al. (2006), que observaram, numa topossequência sob Floresta Ombrófila Mista, no Paraná, que o terço inferior apresentou baixa diversidade florística, devido à maior saturação hídrica no solo, e que a presença de água na superfície do solo, em períodos de elevada precipitação, também justifica o baixo número de espécies. No topo, verificou-se um melhor estado de conservação, uma maior diversidade de espécies e ausência de trechos com acúmulo de água. Os resultados concordam com Juhász et al. (2006), que evidenciaram um domínio de solos profundos e bem drenados no terço superior da topossequência. A elevada umidade no topo pode ser justificada pelos valores superiores de matéria orgânica e argila, pois a presença de matéria orgânica permite a formação e estabilização de unidades estruturais (agregados), aumentando a aeração, a permeabilidade e a capacidade de retenção de água pelo solo (SILVA et al., 2006).

Em relação às características químicas do solo, em profundidade observaram-se valores superiores e significativos na camada de $0-10 \mathrm{~cm}$. Em geral, nas diferentes profundidades, o solo da área de estudo predominou com valores médios de pH baixos (4,06 a 4,70), acidez potencial elevada $(4,46$ a $\left.8,73 \mathrm{cmol}_{\mathrm{c}} / \mathrm{dm}^{3}\right)$, altos teores de alumínio trocável $\left(1,15\right.$ a $\left.2,24 \mathrm{cmol}_{\mathrm{c}} / \mathrm{dm}^{3}\right)$ e reduzidos valores de saturação por bases $(\mathrm{V})$, representada pelas bases trocáveis Ca $\left(0,04\right.$ a $\left.1,14 \mathrm{cmol}_{\mathrm{c}} / \mathrm{dm}^{3}\right), \mathrm{Mg}(0,12$ a $\left.0,96 \mathrm{cmol}_{\mathrm{c}} / \mathrm{dm}^{3}\right)$ e $\mathrm{K}\left(0,04\right.$ a $\left.0,16 \mathrm{cmol}_{\mathrm{c}} / \mathrm{dm}^{3}\right)$, além da baixa disponibilidade de fósforo $(2,87$ a $\left.9,23 \mathrm{mg} / \mathrm{dm}^{3}\right)$ e de carbono orgânico $\left(1,29\right.$ a 3,64 dag. $\left.\mathrm{kg}^{-1}\right)$. Segundo Bohnen et al. (2006), solos de zonas de clima quente e com alta precipitação são, em maioria, ácidos $(\mathrm{pH}<5,5)$, apresentando-se com baixos teores de cálcio $(\mathrm{Ca})$, magnésio $(\mathrm{Mg})$ e potássio (bases trocáveis), e altos de $\mathrm{Al}$.

Resultados similares no comportamento e teores dos nutrientes em profundidade foram encontrados por Feitosa (2004), em uma topossequência predominantemente de Latossolo Amarelo, sob Floresta Ombrófila Densa, em Recife/PE, para as profundidades: 0-5, 5-15 e 15-30 cm, onde os teores médios de $\mathrm{pH}$ variaram entre 4,62 e 4,75, acidez potencial de 4,57 a 5,25 $\mathrm{cmol}_{\mathrm{c}} / \mathrm{dm}^{3}$, Al trocável de 1,35 a $1,68 \mathrm{cmol}_{\mathrm{C}} / \mathrm{dm}^{3}$, Ca de 0,06 a $0,19 \mathrm{cmol}_{\mathrm{c}} / \mathrm{dm}^{3}, \mathrm{Mg}$ de 0,06 a $0,12 \mathrm{cmol}_{\mathrm{c}} / \mathrm{dm}^{3}, \mathrm{~K}$ de 0,08 a $0,12 \mathrm{cmol}_{\mathrm{c}} / \mathrm{dm}^{3}$, P disponível de 3,08 a $6,25 \mathrm{mg} / \mathrm{dm}^{3}$ e teor de carbono orgânico de 3,50 a 3,64 dag. $\mathrm{kg}^{-1}$.

Em condições semelhantes de solo, tipologia florestal e localização, Espig et al. (2008), considerando as profundidades $0-5,5-25,25-45$ e $45-65 \mathrm{~cm}$, também verificaram teores e comportamento de nutrientes compatíveis com estes resultados, como pH $(4,04$ a 4,12), acidez potencial $\left(5,24\right.$ a $\left.8,79 \mathrm{cmol}_{\mathrm{c}} / \mathrm{dm}^{3}\right), \mathrm{Al}\left(1,88\right.$ a $\left.2,05 \mathrm{cmol}_{\mathrm{c}} / \mathrm{dm}^{3}\right), \mathrm{Ca}\left(0,16\right.$ a $\left.0,66 \mathrm{cmol}_{\mathrm{C}} / \mathrm{dm}^{3}\right), \mathrm{Mg}(0,04$ a $\left.0,25 \mathrm{cmol}_{\mathrm{c}} / \mathrm{dm}^{3}\right), \mathrm{K}\left(0,001\right.$ a $\left.0,008 \mathrm{cmol}_{\mathrm{c}} / \mathrm{dm}^{3}\right), \mathrm{P}\left(0,0002 \mathrm{a} 1,96 \mathrm{mg} / \mathrm{dm}^{3}\right)$.

De acordo com o critério de inclusão, verificou-se a ocorrência de 25 espécies arbóreas com, no mínimo, 12 indivíduos (Tabela 1), porém nenhuma delas destacou-se em densidade nas três posições topográficas concomitantemente.

Em relação às características químicas do solo por posição topográfica, apenas a variável fósforo não apresentou diferenças significativas $\left(6,42,5,12\right.$ e $\left.5,26 \mathrm{mg} / \mathrm{dm}^{3}\right)$.

$\mathrm{Na}$ amostragem da baixada, ocorreram 9 espécies, com número mínimo de 12 indivíduos, das quais destacaram-se exclusivamente nesta posição: Tapirira guianensis Aubl., Miconia minutiflora (Bonpl.) DC., Xylopia frutescens Aubl., Pachira aquatica Aubl. e Syzygium jambolanum (Lam.) DC. Entre as variáveis de solo que apresentaram valores superiores e significativos, quando comparadas às demais posições, encontraram-se: pH $(4,61)$, cálcio $\left(0,56 \mathrm{cmol}_{\mathrm{c}} / \mathrm{dm}^{3}\right)$ e magnésio $\left(0,56 \mathrm{cmol}_{\mathrm{c}} / \mathrm{dm}^{3}\right)$, indicando que essas espécies tenderam a ocorrer na posição de maior fertilidade. Segundo Lorenzi (2002a; 2002b; 2003), T. guianensis, o gênero Miconia e $S$. jambolanum são comumente encontradas em situações de solos úmidos, não fazendo inferência à fertilidade. Com relação a $X$. frutescens, o autor associou sua presença a solos com média fertilidade. A espécie $P$. aquatica, que também teve a presença destacada na posição baixada, foi citada por Du Bocage; Sales (2002) como uma espécie que tem desenvolvimento preferencial em ambientes muito úmidos, não citando qualquer informação sobre fertilidade do solo. 
Tabela 1. Espécies com no mínimo 12 indivíduos (N) e suas respectivas densidades absolutas (DA), amostradas nas posições: baixada, encosta e topo, da Reserva Biológica de Saltinho, Tamandaré, Pernambuco, Brasil.

Table 1. Species with at least 12 individuals (N) and their absolute density (DA), sampled at positions: flatland, slope and top of the Saltinho Biological Reserve, Tamandare, Pernambuco, Brazil.

\begin{tabular}{|c|c|c|}
\hline ESPÉCIE & $\mathbf{N}$ & DA (ind./ha) \\
\hline \multicolumn{3}{|l|}{ Baixada } \\
\hline Tapirira guianensis & 103 & 294 \\
\hline Miconia prasina & 84 & 240 \\
\hline Simarouba amara & 77 & 220 \\
\hline Schefflera morototoni & 40 & 114 \\
\hline Miconia minutiflora & 29 & 82 \\
\hline Xylopia frutescens & 22 & 62 \\
\hline Henriettea succosa & 20 & 57 \\
\hline Pachira aquatica & 19 & 54 \\
\hline Syzygium jambolanum & 12 & 34 \\
\hline \multicolumn{3}{|l|}{ Encosta } \\
\hline Eschweilera ovata & 39 & 111 \\
\hline Henriettea succosa & 31 & 88 \\
\hline Brosimum rubescens & 27 & 77 \\
\hline Miconia prasina & 27 & 77 \\
\hline Lacistema pubescens & 23 & 65 \\
\hline Thyrsodium spruceanum & 21 & 60 \\
\hline Protium giganteum & 20 & 57 \\
\hline Protium heptaphyllum & 19 & 54 \\
\hline Bowdichia virgilioides & 16 & 45 \\
\hline Cupania sp. & 16 & 45 \\
\hline Casearia javitensis & 13 & 37 \\
\hline Simarouba amara & 12 & 34 \\
\hline Schefflera morototoni & 12 & 34 \\
\hline \multicolumn{3}{|l|}{ Topo } \\
\hline Protium giganteum & 85 & 242 \\
\hline Brosimum rubescens & 63 & 180 \\
\hline Pogonophora schomburgkiana & 54 & 154 \\
\hline Helicostylis tomentosa & 38 & 108 \\
\hline Eschweilera ovata & 31 & 88 \\
\hline Thyrsodium spruceanum & 27 & 77 \\
\hline Protium heptaphyllum & 20 & 57 \\
\hline Paypayrola blanchetiana & 15 & 42 \\
\hline Brosimum guianense & 13 & 37 \\
\hline Sorocea hilarii & 13 & 37 \\
\hline Cupania racemosa & 12 & 34 \\
\hline Siparuna guianensis & 12 & 34 \\
\hline
\end{tabular}

A encosta apresentou 13 espécies com 12 indivíduos no mínimo, entre as quais destacaram-se com exclusividade: Lacistema pubescens Mart., Bowdichia virgilioides Kunth, Cupania sp. e Casearia javitensis Kunth. Quanto à química do solo, a encosta não apresentou nenhum nutriente com valores superiores e significativos com exclusividade. Esse resultado permite supor que a ocorrência dessas espécies não está preferencialmente condicionada às características químicas do solo, no entanto Lorenzi (2002a) citou B. virgilioides como uma espécie adaptada a terrenos quimicamente pobres.

O topo teve a ocorrência de 12 espécies, destacando-se com no mínimo 12 indivíduos: Pogonophora schomburgkiana Miers ex Benth., Helicostylis tomentosa (Poepp. \& Endl.) Rusby, Paypayrola blanchetiana Tul., Brosimum guianense (Aubl.) Huber, Sorocea hilarii Gaudich., Cupania racemosa (Vell.) Radlk. e Siparuna guianensis Aubl. O solo apresentou valores superiores e 
significativos no teor acidez potencial $\left(7,47 \mathrm{cmol}_{\mathrm{c}} / \mathrm{dm}^{3}\right)$ e no carbono orgânico total $(2,68 \mathrm{dag} / \mathrm{kg})$, sugerindo-se que essas espécies podem ser mais exigentes em matéria orgânica. Segundo Silva et al. (2006), o teor de argila no solo contribui para uma maior concentração de matéria orgânica, e os teores elevados de acidez ocorrem como uma das consequências da formação dos ácidos orgânicos, no processo de decomposição da matéria orgânica.

Ocorreram na baixada e na encosta as espécies Miconia prasina (Sw.) DC., Simarouba amara Aubl., Schefflera morototoni (Aubl.) Maguire, Steyerm. \& Frodin e Henriettea succosa (Aubl.) DC., com 12 indivíduos no mínimo. No solo, foram observados valores superiores e significativos para o nutriente potássio $\left(0,12\right.$ e $0,12 \mathrm{cmol}_{\mathrm{c}} / \mathrm{dm}^{3}$, respectivamente), dado que contribuiu para confirmar que a posição de baixada apresentava a maior fertilidade entre as demais estudadas.

A encosta e o topo tiveram ocorrência em comum das espécies Protium giganteum Engl., Brosimum rubescens Taub., Eschweilera ovata (Cambess.) Miers, Thyrsodium spruceanum Benth. e Protium heptaphyllum (Aubl.) Marchand, e, no solo, teores superiores e significativos de alumínio trocável (1,52 e 1,85 $\mathrm{cmol}_{\mathrm{c}} / \mathrm{dm}^{3}$, respectivamente), que está associado à acidez elevada no topo, pois, na presença de matéria orgânica, ocorre retenção preferencial de cátions trocáveis de maior valência (SILVA et al., 2006). Segundo Lorenzi (2002b), E. ovata tem ocorrência preferencial em terrenos bem drenados e T. spruceanum é indiferente às condições de umidade no solo.

As posições de baixada e topo, concomitantemente, não apresentaram nenhuma relação significativa nas variáveis químicas do solo, como também entre espécies de maiores densidades.

No diagrama de ordenação (Figura 4), os eixos da CCA representam a contribuição relativa de cada componente para explicar a variação total dos dados. As parcelas por posições topográficas estão representadas como pontos ótimos no espaço bidimensional. As variáveis químicas do solo aparecem como vetores ou flechas, indicando a direção das mudanças dessas variáveis no espaço de ordenação (VALENTIN, 2000). Os autovalores (eigenvalues) foram 0,630 para o eixo $1,0,179$ para o eixo 2 e 0,100 para o eixo 3. Felfili; Resende (2003) citaram que quando um autovalor é superior a 0,3 , o componente é considerado de forte relevância na determinação da variação dos dados. Assim, os autovalores para os eixos 2 e 3 foram considerados baixos. No entanto, as maiores correlações espécies-variáveis foram apresentadas para os eixos 1 e $2(0,932 ; 0,851)$, respectivamente. O eixo 1 explicou $21,1 \%$ e o eixo 2 , $6,0 \%$ da variância. Ter Braak, citado por Campos et al. (2006), considerou que baixas porcentagens de variação são esperadas em ordenações de dados ecológicos, devido à complexidade dos fatores envolvidos na estrutura e florística das formações vegetacionais.

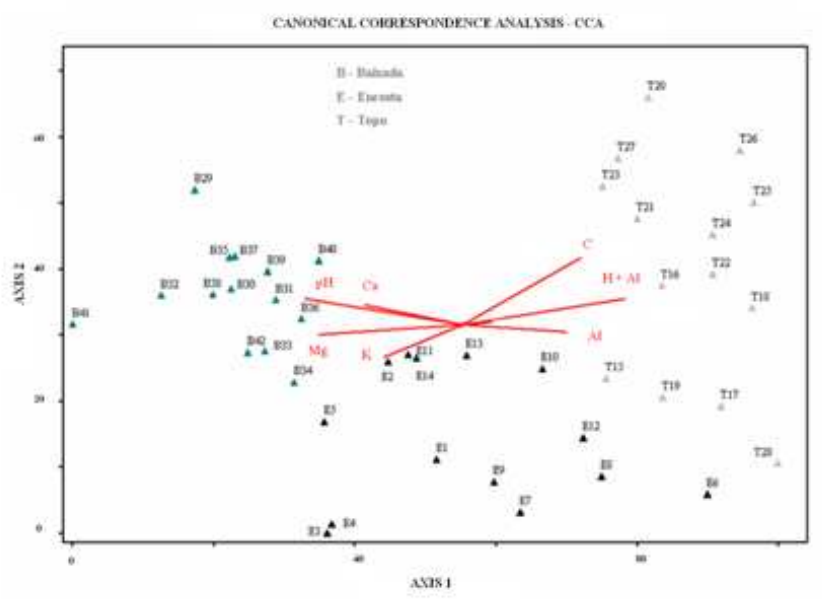

Figura 4. Diagrama de ordenação das variáveis químicas do solo e as posições topográficas (baixada, encosta e topo), nos eixos 1 e 2 da CCA, produzidos a partir da densidade absoluta das espécies que apresentaram no mínimo 12 indivíduos, amostradas na Mata Alta, Tamandaré, Pernambuco, Brasil.

Figure 4. Diagram of chemical ordering of the variables of soil and topographic position (flatland, slope and top), the axes 1 and 2 of the CCA produced from the absolute density of species that had at least 12 individuals, sampled in the Mata Alta, Tamandare, Pernambuco, Brazil. 


\section{CONCLUSÕES}

- A vegetação arbórea na posição de baixada obteve a menor similaridade florística quando comparada às posições de encosta e topo, no entanto foi nessa posição que ocorreu a maior similaridade florística entre parcelas, característica que está diretamente relacionada à menor riqueza de espécies nesse ambiente.

- Áreas mais baixas tendem a acumular, com mais intensidade, água e materiais sólidos do solo, provenientes ou não das áreas mais altas (encosta e topo). Consequentemente, na posição de baixada observaram-se maiores teores de umidade, silte e areia.

- No aspecto químico, a baixada apresentou maiores teores de cálcio, magnésio e potássio, bases trocáveis que dão indicativos da fertilidade do solo, entretanto o menor valor de $\mathrm{pH}$ indica a elevada acidez no solo, podendo indisponibilizar esses nutrientes.

- Na posição de topo, observaram-se teores superiores de umidade, argila, alumínio trocável, acidez potencial e carbono orgânico, características que contribuem nos processos de deposição e decomposição da matéria orgânica no solo.

- Na correlação entre a densidade das espécies arbóreas e as variáveis químicas do solo, ocorreram aquelas com desenvolvimento preferencial na baixada, posição que se apresentou superior em fertilidade, e no topo, que se mostrou superior no teor de matéria orgânica, entretanto a correlação não foi suficiente para explicar, com precisão, a distribuição das espécies arbóreas no gradiente topográfico, sugerindo-se novos estudos com mais fatores ambientais e biológicos para explicar a variação total dos dados.

\section{AGRADECIMENTOS}

Ao técnico e estudantes do curso de graduação em Agronomia da UFRPE, pela colaboração na amostragem e análises dos solos.

\section{REFERÊNCIAS}

AGÊNCIA ESTADUAL DE MEIO AMBIENTE E RECURSOS HÍDRICOS (CPRH). Diagnóstico sócio ambiental: litoral sul de Pernambuco. Recife: CPRH, 2001.

BARBOSA, M. R. V.; SOTHERS, C.; MAYO, S.; GAMARRA-ROJAS, C. F. L.; MESQUITA, A. C. (Orgs.). Checklist das plantas do nordeste brasileiro: angiospermas e gymnospermas. Brasília, DF: Ministério de Ciência e Tecnologia, 2006. 156 p.

BOHNEN, H.; MEURER, E. J.; BISSANI, C. Solos ácidos e solos afetados por sais. In: MEURER, E. J. (Ed.). Fundamentos de química do solo. Porto Alegre: Evangraf, 2006, p. 163-183.

BRAGA, J. M.; DEFELIPO, B. V. Determinação espectrofotométrica de fósforo em extratos de solos e planta. Revista Ceres, Viçosa, MG, v. 21, n. 113, p. 73-85, jul./ago. 1974.

CAMPOS, E. P.; DUARTE, T. G.; NERI, A. V.; SILVA, A. F.; MEIRA-NETO, J. A. A.; VALENTE, G. E. Composição florística de um trecho de cerradão e cerrado sensu stricto e sua relação com o solo na Floresta Nacional (FLONA) de Paraopeba, MG, Brasil. Revista Árvore, Viçosa, MG, v. 30, n. 3, p. 471479, maio/jun. 2006.

CRONQUIST, A. The evolution and classification of flowering plants. New York: New York Botanical Garden, 1988. 555 p.

CUNHA, L. O.; FONTES, M. A. L.; OLIVEIRA, A. D.; OLIVEIRA-FILHO, A. T. Análise multivariada da vegetação como ferramenta para avaliar a reabilitação de dunas litorâneas mineradas em Mataraca, Paraíba, Brasil. Revista Árvore, Viçosa, MG, v. 27, n. 4, p. 503-515, jul./ago. 2003.

CURCIO, G. R.; BONNET, A.; PESTANA, D.; SOUZA, L.; SOCHER, L. G.; GALVÃO, F.; RODERJAN, C. V. Compartimentação topossequencial e caracterização fitossociológica de um capão de Floresta Ombrófila Mista. Floresta, Curitiba, v. 36, n. 3, p. 361-369, set./dez. 2006. 
DUARTE, T. G. Florística, fitossociologia e relações solo-vegetação em Floresta Estacional Decidual em Barão Melgaço, Pantanal de Mato Grosso. 144 f. Tese (Doutorado em Botânica) - Universidade Federal de Viçosa, Viçosa, MG, 2007.

DU BOCAGE, A. L.; SALES, M. F. A família Bombacaceae Kunth. no Estado de Pernambuco, Brasil. Acta Botanica Brasilica, São Paulo, v. 16, n. 2, p. 123-139, abr./maio. 2002.

EMBRAPA - EMPRESA BRASILEIRA DE PESQUISA AGROPECUÁRIA. Centro Nacional de Pesquisa de Solos. Manual de métodos de análise de solo. 2. ed. Rio de Janeiro: Embrapa Solos, 1997. 212 p.

ESPIG, S. A.; FREIRE, F. J.; MARANGON, L. C.; FERREIRA, R. L. C.; FREIRE, M. B. G. S.; ESPIG, D. B. Distribuição de nutrientes entre a vegetação florestal e o solo em fragmento de mata atlântica. Revista Brasileira de Ciências Agrárias, Recife, v. 3, n. 2, p. 132-137, abr./jun. 2008.

FEITOSA, A. A. N. Diversidade de espécies florestais arbóreas associadas ao solo em topossequência de um fragmento de mata atlântica de Pernambuco. 102 f. Dissertação (Mestrado em Ciência do Solo) - Universidade Federal Rural de Pernambuco, Recife, 2004.

FELFILI, J. M.; REZENDE, R. P. Conceitos e métodos em fitossociologia. Brasília, DF: UnB, 2003. 68 p.

GAUCH, H. G. J. Multivariate analysis in community ecology. Cambridge: Cambridge University Press, 1982. 298 p.

INSTITUTO BRASILEIRO DO MEIO AMBIENTE E DOS RECURSOS NATURAIS RENOVÁVEIS (IBAMA). Resumo executivo do plano de manejo da Reserva Biológica de Saltinho. Brasília, DF: IBAMA, 2003. $25 \mathrm{p}$.

JUHÁSZ, C. E. P.; CURSI, P. R.; COOPER, M.; OLIVEIRA, T. C.; RODRIGUES, R. R. Dinâmica físico-hídrica de uma topossequência de solos sob savana florestada (cerradão) em Assis, SP. Revista Brasileira de Ciência do Solo, Viçosa, MG, v. 30, n. 3, p. 401-412, maio/jun. 2006.

LORENZI, H. Árvores brasileiras: manual de identificação e cultivo de plantas arbóreas nativas do Brasil. 4 ed. Nova Odessa: Plantarum, 2002a. v.1.

LORENZI, H. Árvores brasileiras: manual de identificação e cultivo de plantas arbóreas nativas do Brasil. 2 ed. Nova Odessa: Plantarum, 2002b. v. 2..

LORENZI, H.; SOUZA, H. M.; TORRES, M. A. V.; BACHER, L. B. Árvores exóticas no Brasil: madeireiras, ornamentais e aromáticas. Nova Odessa: Plantarum, 2003. 386 p.

MARANGON, L. C.; SOARES, J. J.; FELICIANO, A. L. P.; BRANDÃO, C. F. L. S. Estrutura fitossociológica e classificação sucessional do componente arbóreo de um fragmento de Floresta Estacional Semidecidual, no município de Viçosa, Minas Gerais. Cerne, Lavras, v. 13, n. 2, p. 208-221, abr./jun. 2007.

MCCUNE, B.; MEFFORD, M. J. PC-ORD version 4.14: multivariate analysis of ecological data. MjM Software Design: Oregon, 1999. 237 p.

MOBOT, Missouri Botanical Garden, 2008. Disponível em: <http://www.tropicos.orgNameSearch.aspx?name>. Acesso em: 28/12/2008.

MORENO, M. I. C.; SCHIAVINI, I. Relação entre vegetação e solo em um gradiente florestal na Estação Ecológica do Panga, Uberlândia (MG). Revista Brasileira de Botânica, São Paulo, v. 24, n. 4, p. 537544, dez. 2001. Suplemento.

PEREIRA, M. S.; ALVES, R. R. N. Composição florística de um remanescente de mata atlântica na Área de Proteção Ambiental Barra do Rio Mamanguape, Paraíba, Brasil. Revista de Biologia e Ciências da Terra, Campina Grande, v. 7, n. 1, p. 1-10, jan./jun., 2007.

PINTO-COELHO, R. M. Fundamentos em ecologia. Porto Alegre: Artmed, 2000. 252 p. 
RESENDE, M.; LANI, J. L.; REZENDE, S. B. Pedossistemas da Mata Atlântica: considerações pertinentes sobre a sustentabilidade. Revista Árvore, Viçosa, MG, v. 26, n. 3, p. 261-269, maio/jun. 2002.

ROSSI, M.; QUEIROZ NETO, J. P. Relações solo-paisagem em regiões tropicais úmidas: o exemplo da Serra do Mar em São Paulo, Brasil. Revista do Departamento de Geografia, São Paulo, n. 14, p. 11-23, jun. 2001.

SILVA, L. S.; CAMARGO, F. A. O.; CERETTA, C. A. Composição da fase sólida orgânica do solo. In: MEURER, E. J. (Ed.). Fundamentos de química do solo. Porto Alegre: Evangraf, 2006, p. 63-90.

SIQUEIRA, D. R.; RODAL, M. J. N.; LINS-E-SILVA, A. C. B.; MELO, A. L. Physiognomy, structure and floristic in an area of atlantic forest in northeast Brazil. In: GOTTSBERGER, G.; LIEDE, S. (ed.). Life Forms and Dynamics in Tropical Forest. Gebrüder Borntraeger Verlagsbuchhandlung: Stuttgart, 2001. p. 11-27. (Dissertationes Botanicae).

VALENTIN, J. L. Ecologia numérica: uma introdução à análise multivariada de dados ecológicos. Rio de Janeiro: Interciência, 2000. 117 p.

VELOSO, H. P.; RANGEL FILHO, A. L. R.; LIMA, J. C. A. Classificação da vegetação brasileira, adaptada a um sistema universal. Rio de Janeiro: IBGE, 1991. 123 p.

YEOMANS, J. C.; BREMNER, J. M. A rapid and precise method for routine determination of organic carbon in soil. Communications in Soil Science and Plant Analysis, New Jersey, v. 19, n. 13, p. 1467 $1476,1988$. 